\title{
Percutaneous Mitral Valvotomy in a Case of Situs Inversus Totalis and Juvenile Rheumatic Critical Mitral Stenosis: Case Report
}

\author{
Santosh Kumar Sinha, a, Ramesh Thakur ${ }^{\mathrm{a}}$, Mukesh Jitendra Jha ${ }^{\mathrm{a}}$, Karandeep Singh Sayal ${ }^{\mathrm{a}}$, Mohit Sachan ${ }^{\mathrm{a}}$, \\ Vinay Krishna ${ }^{\mathrm{a}}$, Ashutosh Kumar ${ }^{\mathrm{a}}$, Vikas Mishra ${ }^{\mathrm{a}}$, Chandra Mohan Varma ${ }^{\text {a }}$
}

\begin{abstract}
Situs inversus totalis is a rare congenital disorder where the heart being a mirror image is situated on the right side of the body. Distorted cardiac anatomy makes fluoroscopy-guided percutaneous mitral valvotomy (PMV) technically challenging and there are only few reports of PMV in situs inversus totalis. Here we report a case where PMV was successfully done for situs inversus totalis with rare coincidence of juvenile rheumatic severe mitral stenosis in a 12-year-old boy with a few modifications of standard Inoue technique. He had exertional dyspnea of NYHA class III with initial mitral valve area (MVA) of 0.6 $\mathrm{cm}^{2}$ and severe pulmonary arterial hypertension with features suitable for PMV. Femoral vein was accessed from the left side to align the septal puncture needle and balloon to facilitate left ventricular entry. Septal descent and puncture by Brockenbrough needle was performed in the right anterior oblique view with the needle facing 5 o'clock position. Accura balloon was negotiated across mitral valve in left anterior oblique and procedure was successfully executed. Echocardiography showed a well-divided anterior commissure with an MVA of $2.0 \mathrm{~cm}^{2}$ and mild mitral regurgitation. In summary, PMV is safe and feasible in the rare patient with situs inversus totalis with few modifications of the Inoue technique.
\end{abstract}

Keywords: Dextrocardia; Juvenile rheumatic mitral stenosis; Inoue technique; Percutaneous mitral valvotomy; Situs inversus totalis

\section{Introduction}

Situs inversus totalis refers to the heart being a mirror image situated on the right side with all visceral organs to be mirrored with incidence of approximately 1 in 12,000 people [1], while one in three of these will have situs inversus. Distorted cardiac

Manuscript accepted for publication January 25, 2016

aDepartment of Cardiology, LPS Institute of Cardiology, G.S.V.M. Medical College, Kanpur, Uttar Pradesh 208002, India

${ }^{b}$ Corresponding Author: Santosh Kumar Sinha, Department of Cardiology, LPS Institute of Cardiology, G.S.V.M. Medical College, Kanpur, Uttar Pradesh 208002, India. Email: fionasan@rediffmail.com

doi: http://dx.doi.org/10.14740/jocmr2473w anatomy makes fluoroscopy lguided transcatheter procedures difficult which become technically more challenging in the cases with percutaneous mitral valvotomy (PMV), where the cardiac malpositions substantially increase the complications beginning from interatrial septal puncture to left ventricular entry. There are only few reports on successful percutaneous transvenous mitral commissurotomy (PTMC) in abnormal cardiac anatomy using the standard Inoue technique [2-7]. Here we describe a case of a 12-year-boy with situs inversus totalis, where PTMC was successfully performed with slight modifications of the standard Inoue technique. Mitral valvuloplasty is treatment of choice to correct severe mitral stenosis in a selected subset of patients.

\section{Case Report}

A 12-year-old boy presented with progressive exertional dyspnea NYHA class III of 7 months duration. Blood pressure was $100 / 76 \mathrm{~mm} \mathrm{Hg}$ in right arm in supine position. Pulse rate was $70 / \mathrm{min}$, regular, low volume, with no special character with all peripheral pulses palpable. Jugular venous pulse pressure was elevated $6 \mathrm{~cm}$ above sternal angle with prominent a wave and $\mathrm{v}-\mathrm{y}$ descent. Apex beat was located in right fifth intercostals space, tapping in character. There was grade II right parasternal heave. $\mathrm{P}_{2}$ was palpable. $\mathrm{S}_{1}$ was loud. $\mathrm{S}_{2}$ was loud; loud $\mathrm{P}_{2}$ component with narrow split. Opening snap (OS) was present with narrow $\mathrm{A}_{2}$-OS gap. There was long grade IV mid diastolic rumbling murmur with presystolic accentuation. Pansystolic murmur grade III/VI of tricuspid regurgitation was present in left parasternal area. The electrocardiograph (ECG) showed inverted $P$ wave in all leads except aVR and $V_{1}$, upright $R$ wave in aVR, reduction in the $\mathrm{R}$ wave voltage across the chest leads with evidence of right ventricular hypertrophy (Fig. 1A). Chest X-ray PA view showed dextrocardia (Fig. 1B). Subcotal window showed aorta on the right and inferior vena cava on the left side, i.e. situs inversus (Fig. 1C). Transthoracic echocardiography showed critical mitral stenosis with mitral valve area (MVA) of $0.6 \mathrm{~cm}^{2}$ by pressure half time (Fig. 1D) and planimetry (Fig. 1E) and mild mitral regurgitation. His Wilkin's score was $8 / 16\left(\mathrm{C}_{2}, \mathrm{~T}_{2}, \mathrm{M}_{2}, \mathrm{~S}_{2}\right)$. Mean gradient across mitral valve was $36 \mathrm{~mm} \mathrm{Hg}$. Transesophageal echo ruled out any LA or LAA clot. Dextrocardia, atrio-ventricular (AV) and ventriculoarterial (VA) concordance were present. Left femoral artery 

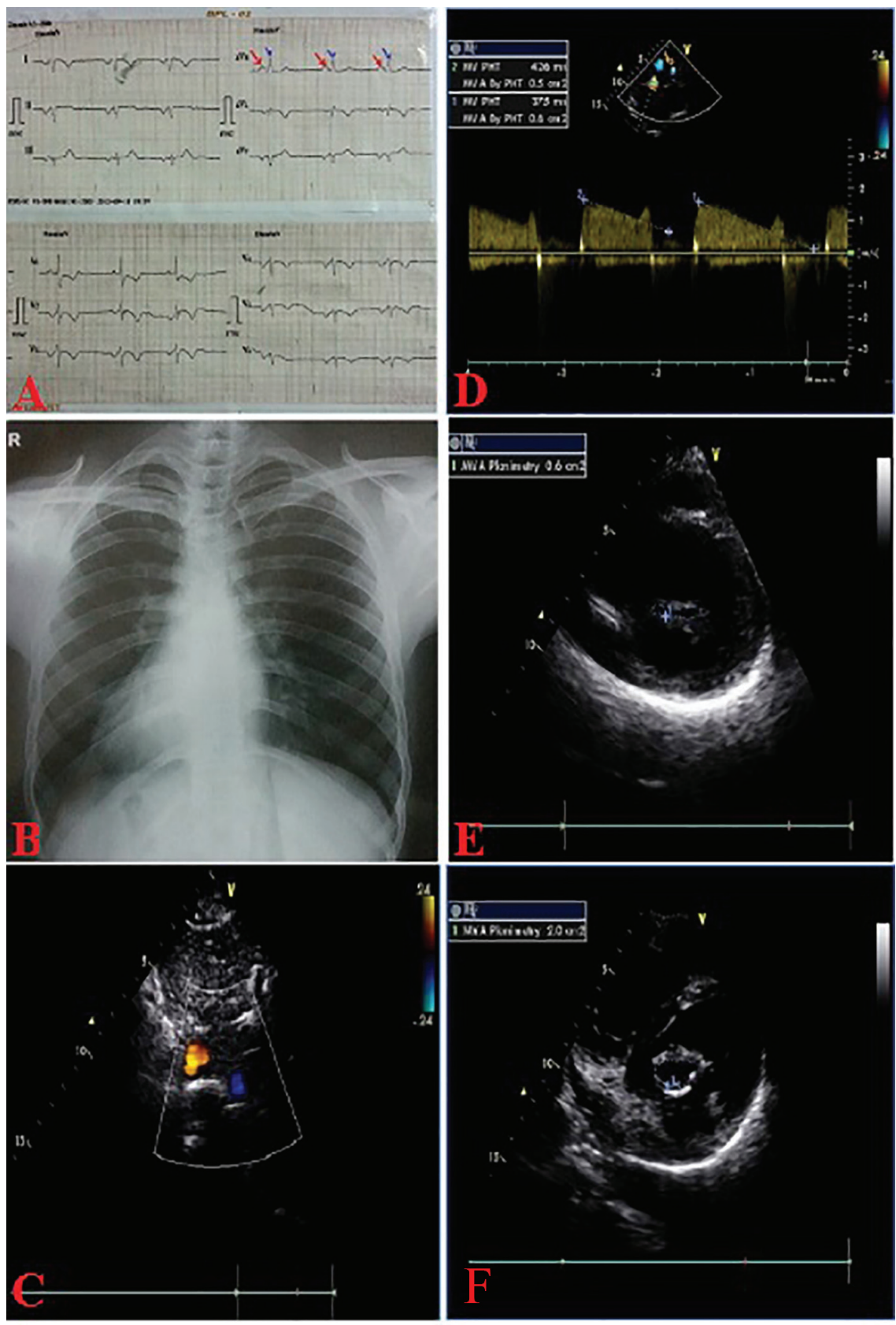

Figure 1. ECG (A); chest X-ray (B) PA view showing situs inversus totalis; subcostal echo showing situs inversus (C), critical MS by PHT (D), planimetry (E), post-PTMC MVA-2.0 $\mathrm{cm}^{2}(\mathrm{~F})$.

and venous access was obtained with a $5 \mathrm{~F}$ arterial and $8 \mathrm{~F}$ venous sheaths, respectively after proper consent. A 5F pigtail catheter was passed retrograde into the aorta and parked in the non-coronary sinus of the aortic root. A 0.035 " J-tip guide wire was then passed up the femoral vein into the inferior vena cava (IVC) and up into the left-sided superior vena cava (SVC) via the left-sided "right atrium" (Fig. 2A). An 8F Mullins sheath was passed up on the guide wire, into the left SVC (Fig. 2B). A curved Brockenbrough septal puncture needle was introduced into the sheath stopping just short of the tip and was oriented to 9 o'clock position in the SVC. Septal descent was done by withdrawing the needle and the sheath in tandem into the heart with the needle pointer in 9 o'clock position. Septal puncture was done in right anterior oblique (RAO) $40^{\circ}$ and also confirmed in left lateral projection which was contrary to our conventional view, i.e., left anterior oblique (LAO) $40^{\circ}$ projection (Fig. 2C). LA was entered and pressure was recorded. The septum was dilated and heparin $100 \mathrm{IU} / \mathrm{kg}$ IV was given. A "loopy" LA wire was then passed through the sheath into LA and the latter was withdrawn leaving the LA wire inside (Fig. 2D). The $14 \mathrm{~F}$ dilator was then used to dilate the septum (Fig. 3A). Subsequently, the accura balloon (Vascular Concepts, Es- 


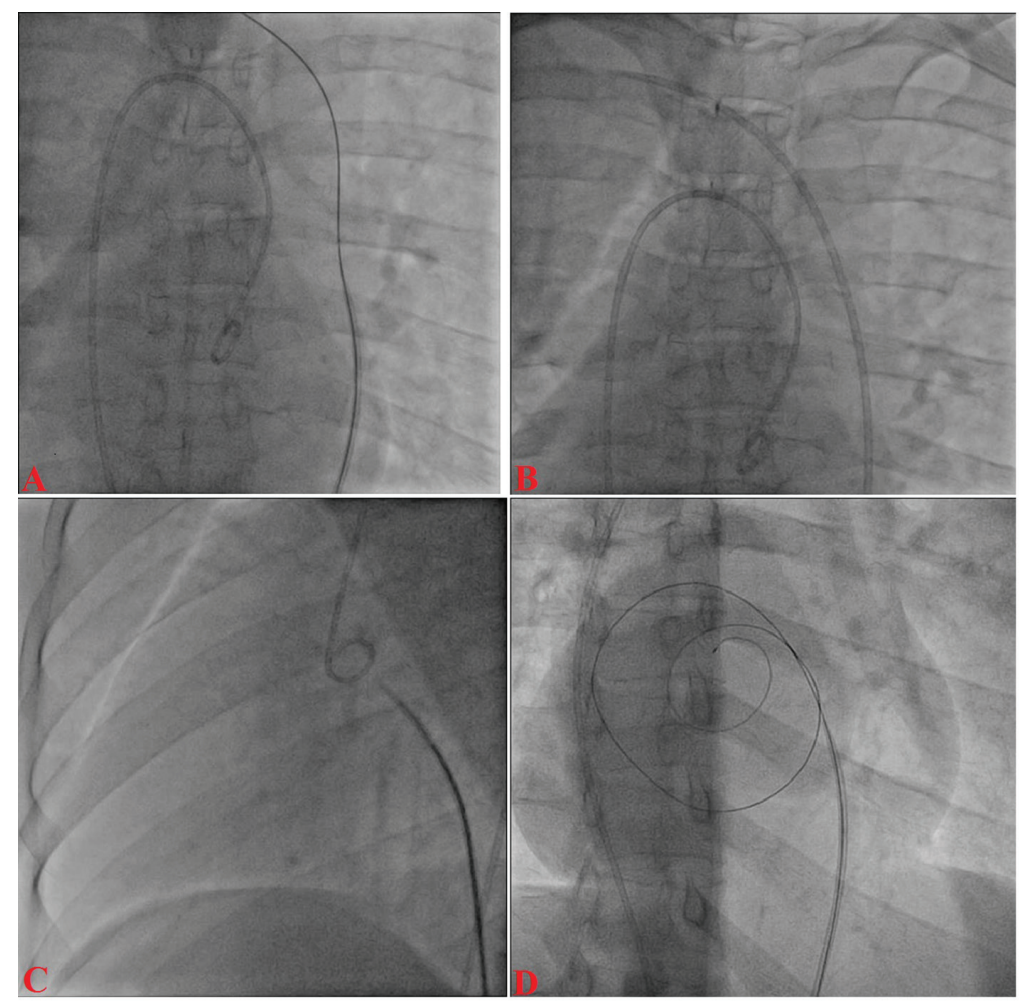

Figure 2. J-tip guide wire into the left-sided superior vena cava (A), 8F Mullins sheath into the left SVC (B); Brockenbrough needle oriented to 9 o'clock position (C); septal puncture (D).

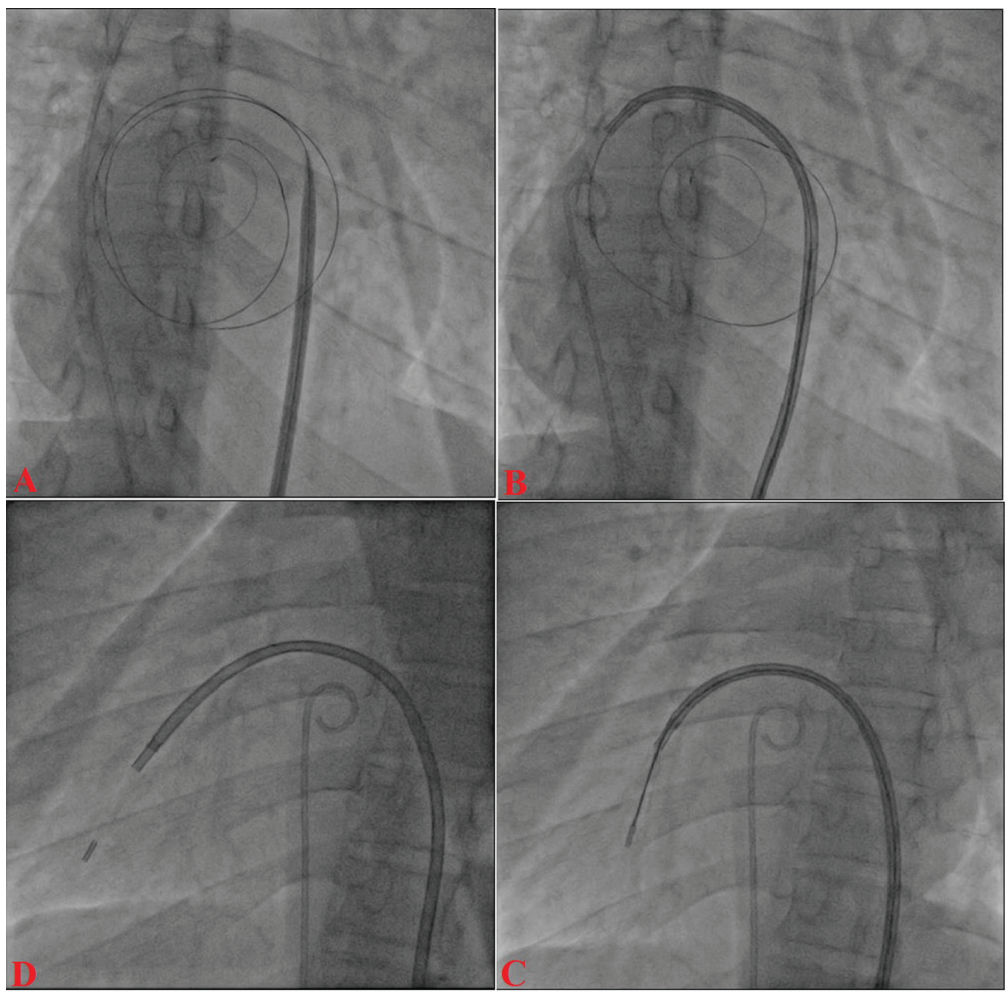

Figure 3. 14F dilator across the septum (A); accura balloon into LA over looped wire (B); director inside the balloon (C); balloon towards mitral valve (D). 


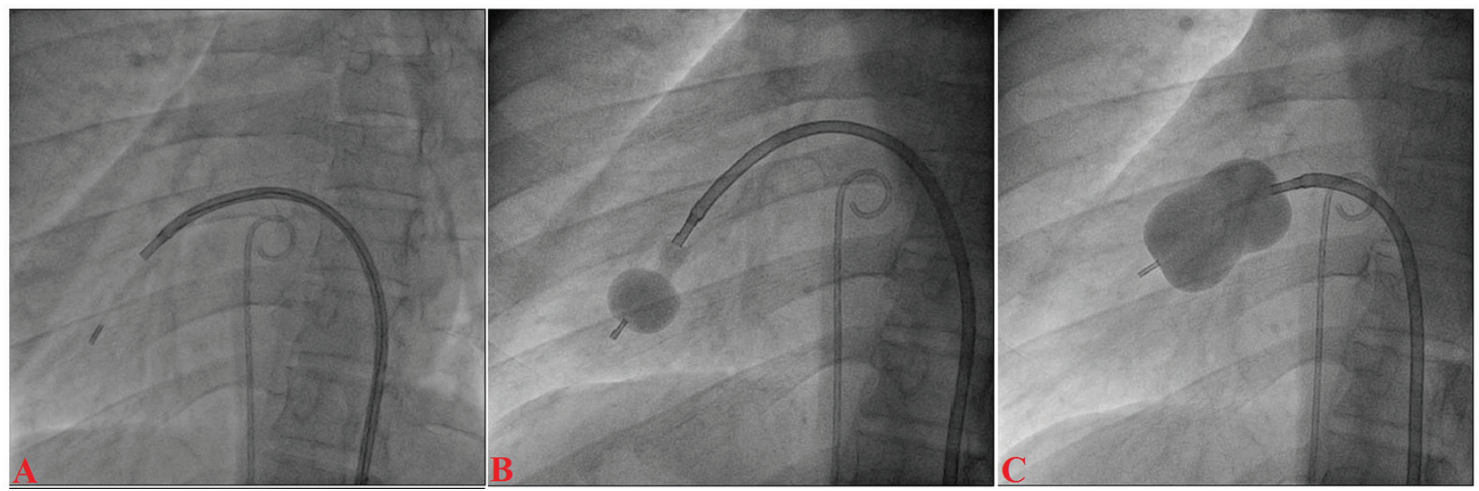

Figure 4. Accura balloon entering into the LV (A); distal inflation of balloon (B); mitral valve dilation (C).

sex, UK) was introduced over the LA wire to enter the LA (Fig. 3B). The LA wire was withdrawn and the balloon was flushed and simultaneous LA/LV pressures were recorded. Now, director was used to guide the balloon (Fig. 3C) towards mitral valve by slight counter clock rotation till flip at the balloon tip was noted (Fig. 3D). Director was pulled and balloon was pushed in a symphony to facilitate its entry into the LV (Fig. 4A). Mitral valve was negotiated and dilation was performed successfully in LAO $40^{\circ}$ projection which was contrary to our conventional view, i.e., RAO $40^{\circ}$ projection (Fig. 4B, C). Postprocedural MVA was $2.0 \mathrm{~cm}^{2}$ and MR still remained mild (Fig. $1 \mathrm{~F})$. Patient was discharged in stable condition on third day.

\section{Discussion}

Mirror-image dextrocardia, as in our case, has been estimated to occur with a prevalence of 1:10,000 patients. However, there are only a few case reports in the literature on PTMC in similar settings [5]. This might be due to the fact that many of these patients undergo surgical commissurotomy due to the technical difficulties involved in a percutaneous procedure in general. Trans-septal catheterization is considered a technical challenge in anatomically malpositioned hearts, as it is fraught with a higher risk of cardiac perforation. It is performed from the left groin as it reduces the puncture needle angulation at the confluence of the iliac veins to the left-sided IVC thus helping to align the tracking of balloon and septal puncture needle with IVC and common iliac vein. The descent of the needle assembly is recommended in mirror-image position, i.e. 7 - 9 o'clock position of the external indicator of the needle instead of its usual 4 - 6 o'clock position [8]. After septal puncture, entry into the LA and its depth can be confirmed by pressure measurement and contrast staining of the left atrium $[5,6,8]$. Septal dilatation is to be done in usual fashion. Accura balloon is mounted over the LA wire. After removing the looped LA wire, director should be entered into accrue balloon and negotiation across the mitral valve should be done in RAO view. Director should be rotated in counter clock fashion. Once the flip at the tip of balloon is observed, director should be removed as it facilitates entry into LV. Thereafter further steps remain the same. Transesophageal and intracardiac echo may be important adjunctive sometimes but also cumbersome otherwise [9]. The trans-jugular approach is thought to overcome many of the technical problems encountered with the transfemoral route in cases with anatomical alterations [10]. Furthermore, the radiographic images can be acquired in the inverted position and can be used as fluoroscopic guidance for septal puncture but this may not be available in many cathlab equipments [5]. All technical modifications have been summarized in Table 1. Despite the challenging anatomy, PTMC has been demonstrated to be a safe and feasible option for MS in patients with unusual cardiac anatomy [10].

\section{Conflict of Interest}

The authors report no financial relationships or conflicts of interest regarding the content herein.

\section{References}

1. Bohun CM, Potts JE, Casey BM, Sandor GG. A population-based study of cardiac malformations and out-

Table 1. Summary of Technical Modifications for PTMC in Dextrocardia

\begin{tabular}{lll}
\hline Steps & Conventional PTMC & PTMC in dextrocardia \\
\hline Trans-septal catheterization & Right groin & Left groin \\
Descent of needle assembly & $4-6$ o'clock position & 7 - 9 o'clock position \\
Septal puncture & AP view & Pseudo AP view \\
& LAO view & RAO view \\
Crossing of mitral valve and balloon dilatation & RAO view & LAO view \\
\hline
\end{tabular}


comes associated with dextrocardia. Am J Cardiol. 2007;100(2):305-309.

2. Raju R, Singh S, Kumar P, Rao S, Kapoor S, Raju BS. Percutaneous balloon valvuloplasty in mirror-image dextrocardia and rheumatic mitral stenosis. Cathet Cardiovasc Diagn. 1993;30(2):138-140.

3. Patel TM, Dani SI, Thakore SB, Chaq MC, Shah SC, Shah UG, Thomas VM, et al. Balloon Mitral and Aortic Valvuloplasty in Mirror-Image Dextrocardia. J Invasive Cardiol. 1996;8(3):164-168.

4. Chow WH, Fan K, Chow TC. Balloon mitral commissurotomy in a patient with situs inversus and dextrocardia. J Heart Valve Dis. 1996;5(3):307-308.

5. Nallet O, Lung B, Cormier B, Porte JM, Garbarz E, Michel PL, Vahanian A. Specifics of technique in percutaneous mitral commissurotomy in a case of dextrocardia and situs inversus with mitral stenosis. Cathet Cardiovasc Diagn. 1996;39(1):85-88.

6. Joseph G, George OK, Mandalay A, Sathe S. Transjugular approach to balloon mitral valvuloplasty helps overcome impediments caused by anatomical alterations. Catheter Cardiovasc Interv. 2002;57(3):353-362.

7. Verma PK, Bali HK, Suresh PV, Varma JS. Balloon mitral valvotomy using Inoue technique in a patient of isolated dextrocardia with rheumatic mitral stenosis. Indian Heart J. 1999;51(3):315-317.

8. Namboodiri N, Harikrishnan SP, Ajitkumar V, Tharakan JA. Percutaneous mitral commissurotomy in a case of mirror-image dextrocardia and rheumatic mitral stenosis. J Invasive Cardiol. 2008;20(1):E33-35.

9. Shalganov TN, Paprika D, Borbas S, Temesvari A, SziliTorok T. Preventing complicated transseptal puncture with intracardiac echocardiography: case report. Cardiovasc Ultrasound. 2005;3:5.

10. Said SA, Veerbeek A, van der Wieken LR. Dextrocardia, situs inversus and severe mitral stenosis in a pregnant woman: successful closed commissurotomy. Eur Heart J. $1991 ; 12(7): 825-828$. 